\title{
A "DORMIÇÃO DA MÃE DE DEUS", A FESTA DA ORTODOXIA E A REPRESENTAÇÃO PÓS-BIZANTINA ATRAVÉS DA ICONOGRAFIA DE THEOPHANIS, O CRETENSE, E DA DESCRIÇÃO DE DIONÍSIO DE FURNA
}

\author{
Fernanda Lemos de Lima* \\ (ILE/PGL/UERJ - PGLC/UFRJ - ABRAFIL)
}

\begin{abstract}
RESUMO: O presente trabalho visa estudar como a representação da passagem de "A dormição da Mãe de Deus", no contexto da ortodoxia grega por meio da comparação entre a iconografia realizada por Theophanis, o Cretense, no monastério de Stavronikita, em 1546; e do modo como o livro Interpretação da técnica de pintura bizantina, escrito entre 1730 e 1734, por Dionísio de Furna, descreve os elementos que deveriam aparecer na cena da "dormição da Mãe de Deus". Tal estudo comparativo visa observar como a pintor, anterior a Dinísio de Furna, apresenta uma interpretação da passagem apócrifa e em que pontos ela difere ou não do modo como o livro indica os elementos a serem representados na imagem, refletindo, desse modo, sobre a liberdade de composição dos pintores, ao criarem imagens da iconografia cristã ortodoxa.

Palavras-Chave: Dionísio de Furna; Theophanis, o Cretense; iconografia bizantina; pintura bizantina
\end{abstract}

\author{
"SLEEPING OF THE MOTHER OF GOD", THE ORTHODOXY \\ CELEBRATION E THE POST-BYZANTINE REPRESENTATION \\ THROUGH THE ICONOGRAPHY OF THEOPHANIS THE CRETAN AND \\ THE DESCRIPTION OF DIONISOS OF FURNA
}

\begin{abstract}
The present work aims to study how the representation of the passage of "The Dormition of the Mother of God", in the context of Greek orthodoxy, through the comparison between the iconography realized by Theophanis the Cretan in the monastery of Stavronikita, in 1546, and the way in which the book Interpretation of the Byzantine painting technique, written between 1730 and 1734, by Dionisio o Furna, describes the elements that should appear in the "Dormition of the Mother of God" scene. This comparative study aims to observe how the painter, prior to Dinisio de of Fourna, presents an interpretation of the apocryphal passage and in what points it differs or not from the way the book indicates the elements to be represented in the image, thus reflecting on the freedom of composition of painters, when creating images of orthodox Christian iconography.
\end{abstract}

KEYWORDS: Dionisio of Furna; Theophanis the Cretan; Byzantine iconography; Byzantine painting

\footnotetext{
*E-mail: fernandalimagr@gmail.com
} 


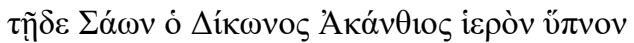

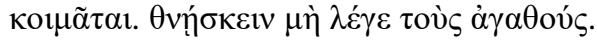

Aqui Sáon, o acântio virtuoso, sagrado sono dorme. Não diga que os bons morrem.

(Calímaco de Cirene)

Na literatura do período helenístico, de onde é pinçada a epígrafe do presente estudo, há a admoestação da ideia de "dormir" como substituição ao uso da palavra "morrer", especialmente para os considerados "bons", com o intuito de negar o fim da vida daqueles que

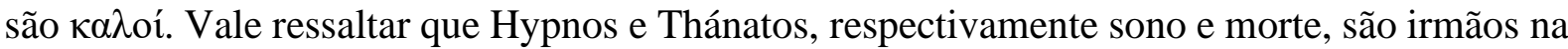
mitologia grega e, portanto, a ligação entre essas duas imagens já remonta a uma ancestralidade da cultura helênica anterior ao Cristianismo. Não se pode negar a continuidade de uma série de pontos do helenismo na tradição das igrejas cristãs, católica e ortodoxa. Aqui, gostaria de chamar a atenção para o que significa a "Dormição de Maria", a "mãe de Deus", no referido contexto cristão do catolicismo e da ortodoxia: trata-se, curiosamente, de como é denominado o momento de sua morte, percebida como um "dormir" a caminho da vida eterna. A mãe do Cristo não morre, ela adormece e tem a alma conduzida por seu filho até o reino dos céus.

Segundo Burke ${ }^{1}$, para interpretar a mensagem, é necessário familiarizar-se com códigos culturais, ou seja, para compreender o lugar histórico-religioso da "Dormição de Maria" na ortodoxia grega e em sua iconografia sagrada, é preciso entender o lugar religioso-cultural ocupado pela mulher que gerou o Deus feito homem. Ao procurar entender a importância da mãe de Deus na ortodoxia grega, é possível notar a força do apócrifo como narrativa legitimada pela iconografia. Digo isso por perceber, no interior do edifício eclesiástico das igrejas ortodoxas gregas, um microcosmo cristão pintado, trazendo uma narrativa imagética para os fiéis baseada tanto nos textos canônicos quanto nos apócrifos, esses últimos são textos teoricamente não oficiais do cristianismo. Nesse exato contexto, há a iconografia que serve de tema central ao presente trabalho, a pintura da Koí nome grego para a celebração da "Dormição de Maria, mãe de Deus".

O presente trabalho pretende observar a representação da passagem de extrema importância para o calendário litúrgico ortodoxo, a partir de uma iconografia do século XVI e de um texto sobre hagiografia datado do século XVIII. A pintura a ser estudada é "A dormição da Mãe de Deus" realizada por Theophanis o Cretense ${ }^{2}$, no monastério de Stavronikita, em 1546. O livro é Interpretação da técnica de pintura bizantina ${ }^{3}$, escrito entre 1730 e 1734, por Dionísio de Furna ${ }^{4}$. Vale ressaltar o fato de a Obra de Dionisio ser bastante posterior à pintura de Theophánis, todavia, é relevante mencionar que ele aprendeu muito do pintor de Creta e o teve como grande influência em sua produção iconográfica.

\footnotetext{
${ }^{1}$ apud QUIRICO, Tamara. As funções do Juízo final como imagem religiosa. In: História [online]. 2010, vol.29, n.1, p. 125 .

2 Theophanis, o cretense ou Theophanis Bathas Strelitzas foi um dos expoentes da escola cretense de iconografia cristã do século XVI. Suas pinturas estão presentes. Fez parte do atelier de Ritsos e tem obras tanto em igrejas de Creta como em Ágios Oros. É considerado o mais importante hagiógrafo do período.

${ }^{3}$ O título é traduzido por "manual", entretanto, a palavra grega que inicia o título original é "interpretação". Prefiro utilizar a tradução literal do nome, uma vez que ela confere uma acepção especial ao título da obra, não sendo apenas um manual, mas um livro que prevê interpretação da pintura bizantina.

${ }^{4}$ Dionísio de Furna foi um monge nascido em 1670, filho de um sacerdote, que aos 16 anos vai ao Monte Athos e se torna um iconógrafo. Incialmente foi influenciado pela pintura de Pansélinos - nome importantíssimo na iconografia bizantina - mas sua técnica iconográfica será devedora igualmente da iconografia cretense de Theophánis de Creta. Foi responsável pela pintura de uma capela dedicada a São João Batista, além da capela de São Dimítrios no monastério de Vatopedí, no monte Atos.
} 
Para apreciar mais profundamente a imagem iconográfica presente no interior do edifício eclesiástico da Ortodoxia Grega e poder observar em detalhe o trabalho de Theophánis, o cretense, além da relevância das festas theomitóricas ${ }^{5}$, é preciso compreender o lugar da passagem da "Dormição" no ambiente religioso em que ela se inscreve.

O episódio da "Dormição" está registrado em vários textos apócrifos, não sendo mencionada nos textos canônicos da Bíblia da ortodoxia grega. Esse dado é relevante e, traz um elemento de valor diferenciado da fonte da iconografia da "Dormição". Panogiótis Zisidis, em sua tese de doutorado sobre o tema, fala a respeito da visão mais vulgar do termo "apócrifo", como um texto menos relevante e crível. Todavia, chama a atenção para o significado primeiro do vocábulo, como algo a ser "escondido e bem guardado", o que denota o valor da obra. A partir dessa reflexão, pode-se começar a compreender porque essa passagem encerra o calendário litúrgico, no contexto da religião em questão, sendo uma festividade de tamanha importância a ponto de se iniciar no primeiro dia de agosto, pressupondo um jejum até a festa do dia 15 do mesmo mês. Nesse contexto, agosto é considerado o mês dedicado à Mãe de Deus.

De acordo com o portal Ecclesia ${ }^{7}$, com base no livro $O$ ano litúrgico ortodoxo, "A celebração dessa solenidade no dia 15 de agosto foi fixada com um edito do imperador do Oriente, Maurício (582-602), confirmando uma tradição, sem dúvida, mais antiga”. Ou seja, ao lidar com a imagem escolhida, estou entrando no universo de uma celebração das mais antigas dentro do calendário das igrejas cristãs do Oriente. ${ }^{8}$ Tal dado indica a importância da imagem estudada aqui. Além disso, sua presença frequente no interior das igrejas bizantinas e da ortodoxia grega indica a relevância dessa celebração, popularmente conhecida como "Páscoa do verão", no ambiente helênico contemporâneo.

Ademais, é interessante pensar como a celebração da figura feminina é forte dentro da

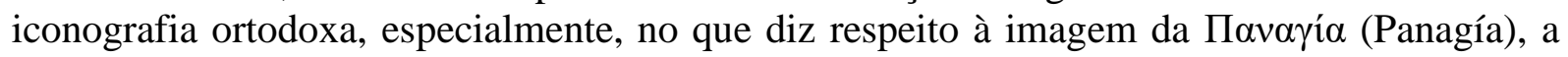
toda santa. Dos quinze ícones pintados por Theophánis, o Cretense, e publicados em pranchas, na edição feita pelo próprio monastério, sete trazem a Mãe de Deus como elemento central ou como deuteragonista em relação a Cristo, na cena retratada. Esse detalhe, que poderia parecer de pouca importância, revela, em verdade, o lugar preponderante do culto à Panagía nesse contexto do cristianismo.

As imagens em que a Mãe de Deus é retratada pelo cretense são a "Anunciação à Mãe de Deus", "O nascimento do Cristo", "A apresentação de Jesus no templo", "A crucificação", "A saudação às miroforas", "A ascensão" e "A dormição da Mãe de Deus". Apenas pela quantidade de imagens em que a figura feminina da mãe aparece, já é perceptível a grande relevância de sua celebração na Ortodoxia Grega, especialmente, ao se levar em conta que é a figura feminina aquela a terminar o calendário litúrgico e, ao mesmo tempo, é a anunciação à Maria que inicia o ano litúrgico. Ou seja, do início ao fim, a figura materna estará nas pontas dessas narrativas.

Interessa especialmente, ao presente estudo, a última iconografia de Theophanis, presente na publicação, que pode dialogar com as orientações do já mencionado livro de Dionísio de Furna. A cena da "Dormição da Mãe de Deus", de acordo com a Interpretação da técnica de pintura bizantina, é descrita nos seguintes termos:

Casas e, no meio, a Panagía deitada sobre um leito, morta, tendo as mãos cruzadas sobre (o peito) e, junto ao leito de um lado e de outro,

\footnotetext{
5 Adjetivo que significa “da Mãe de Deus”.

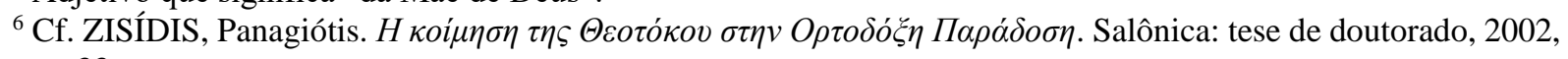
p. 33.

${ }^{7}$ http://www.ecclesia.com.br/biblioteca/liturgia/doze_festas_dormicao.html

${ }^{8}$ No presente trabalho, não tratarei da celebração nas igrejas cristãs do Ocidente.
} 
candelabros com velas acesas; um judeu diante do leito, tendo as mãos decepadas, penduradas no leito, e, diante dele, um anjo com a espada sacada. E, junto aos pés dela, o apóstolo Pedro incensando com incensório, e, junto à cabeça dela, São Paulo e João Teólogo se despedindo dela; e, em torno, os outros apóstolos e os santos hierarcas, Dionisio Aeropagita, Hieróteo e Timóteo, carregando os Evangelhos, e mulheres chorando. E sobre ela, o Cristo carregando em seus braços a santa alma dela envolta em branco ${ }^{9}$; e, em torno de sua luz, uma multidão de anjos, e, mais acima (pairando no ar), novamente os doze apóstolos vindo em meio a nuvens; e na extremidade direita da casa, João Damasceno, carregando um escrito ${ }^{10}$ diz: "Merecidamente, a alma é recebida no céu, celeste, toda pura, divina fortaleza e protetora" etc.; e, à esquerda, São Kosmá, o poeta, carregando um escrito, diz: "Mulher mortal, mas extraordinária e mãe de Deus conhecido, toda inocente" etc. ${ }^{11}$

O trecho acima é retirado à quinta parte da obra de Dionísio de Furna, cujo titulo da primeira seção é "Como são contadas as festas theomitórikas (da mãe de Deus)", dado sintomático da importância das celebrações da Panagía no ambiente Bizantino e da ortodoxia grega. A riqueza de detalhes com que é descrita a cena faz com que, mesmo sem ter a iconografia diante dos olhos, seja possível vislumbrar o evento esplendoroso do sono/morte de Maria e do Cristo a carregar sua alma pura como a de um recém-nascido, para os céus. A miríade de anjos a compor o cortejo é outro detalhe relevante, para além da presença dos apóstolos determinados, aos pés e cabeceira do leito, e dos doze apóstolos no céu. Um detalhe que aparece na descrição e nem sempre está presente nas iconografias da "Dormição" é a figura do judeu que tem as mãos decepadas por um anjo. Esse detalhe está presente na Homilia à Dormição da Virgem, de João de Salônica ${ }^{12}$. É relevante mencionar essa variação, pois a obra de Theophánis a ser estudada não apresenta essa figura.

\footnotetext{
${ }^{9}$ Em faixas brancas, como as que envolvem um recém-nascido.

${ }^{10}$ Em grego, há a palavra $\chi \alpha \rho \tau i ́$, que significa papel, mas pode ser traduzida por papel escrito ou escrito.

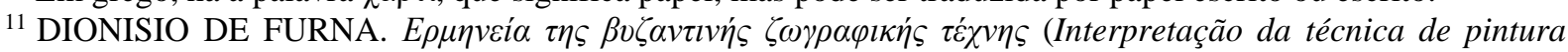
bizantina). Atenas: Spanós, 1997, p. 114-145. Minha tradução do grego.

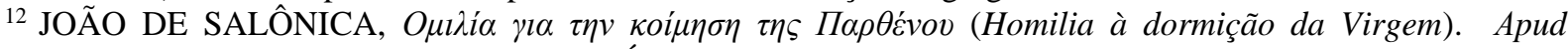

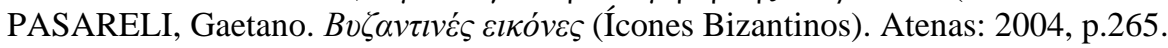




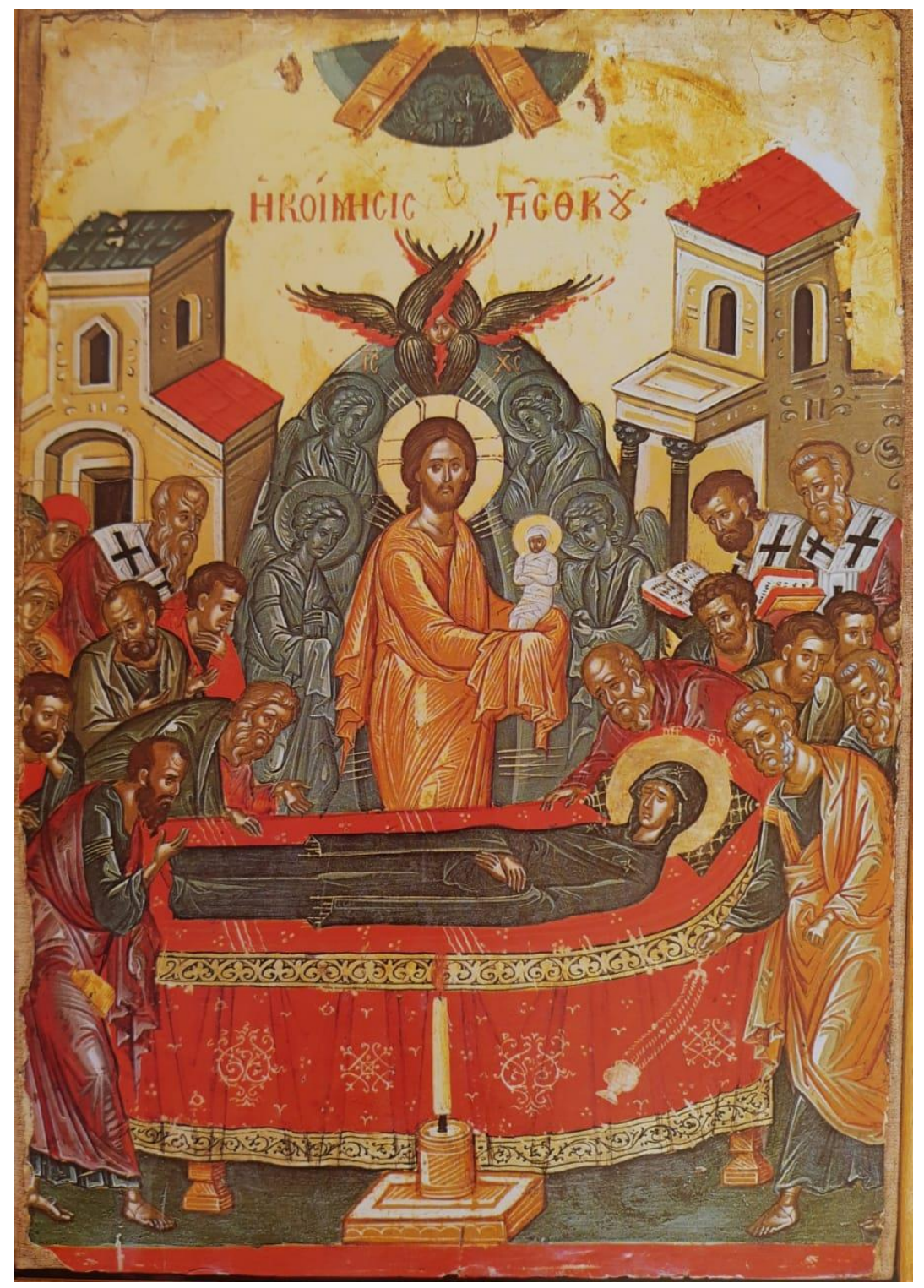

A imagem da "Dormição" elaborada por Theophanis traz a seguinte disposição de elementos: Theotókos deitada sobre um leito, com a cabeça para a direita e as mãos cruzadas na altura da barriga. Imediatamente diante de seu leito, há uma única vela centralizada na cena e cuja verticalidade vai em direção da figura do Cristo, a qual tem a alma imaculada de sua mãe nas mãos, como num gesto de apresentar a recém-nascida para a vida eterna. 


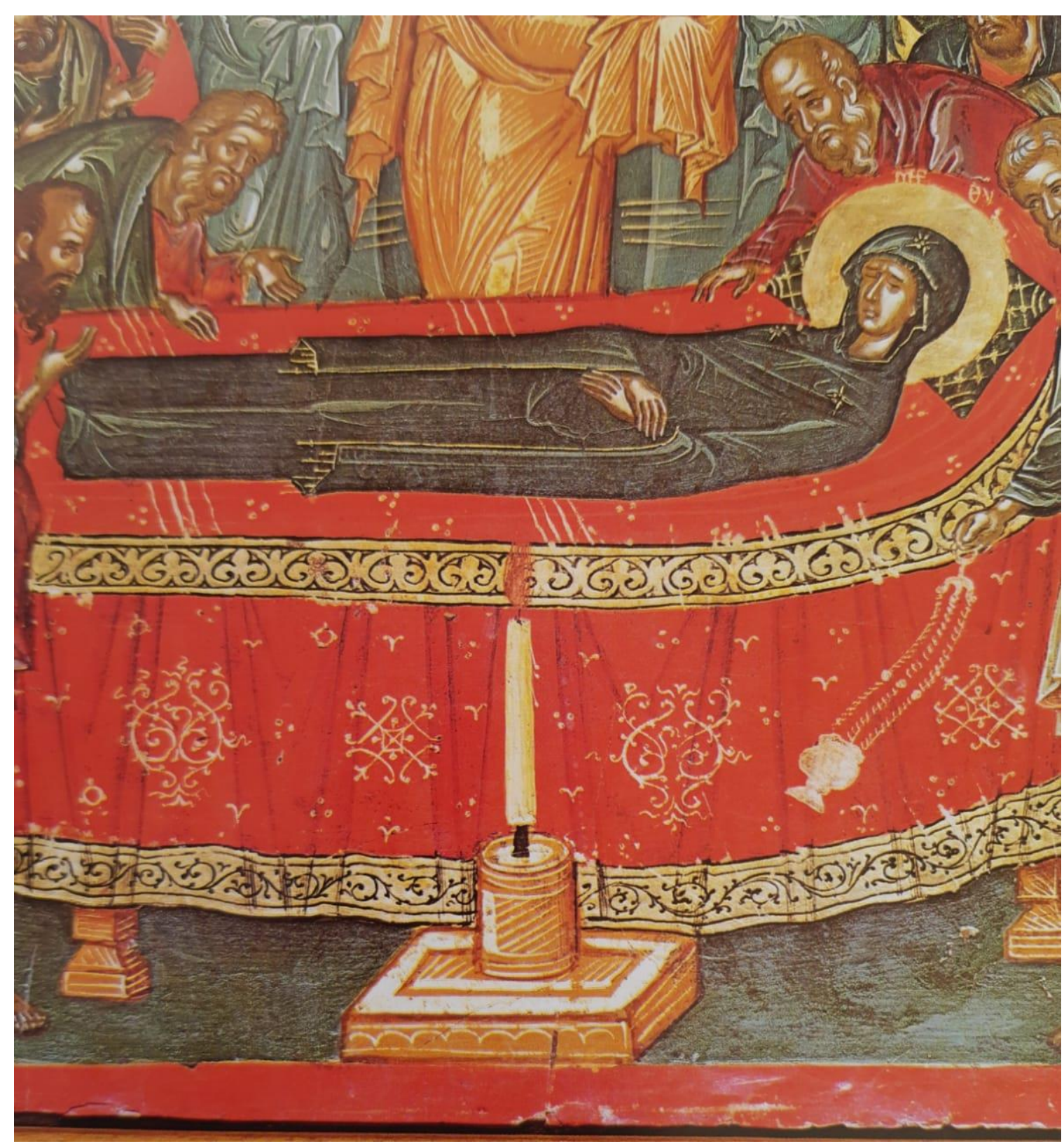




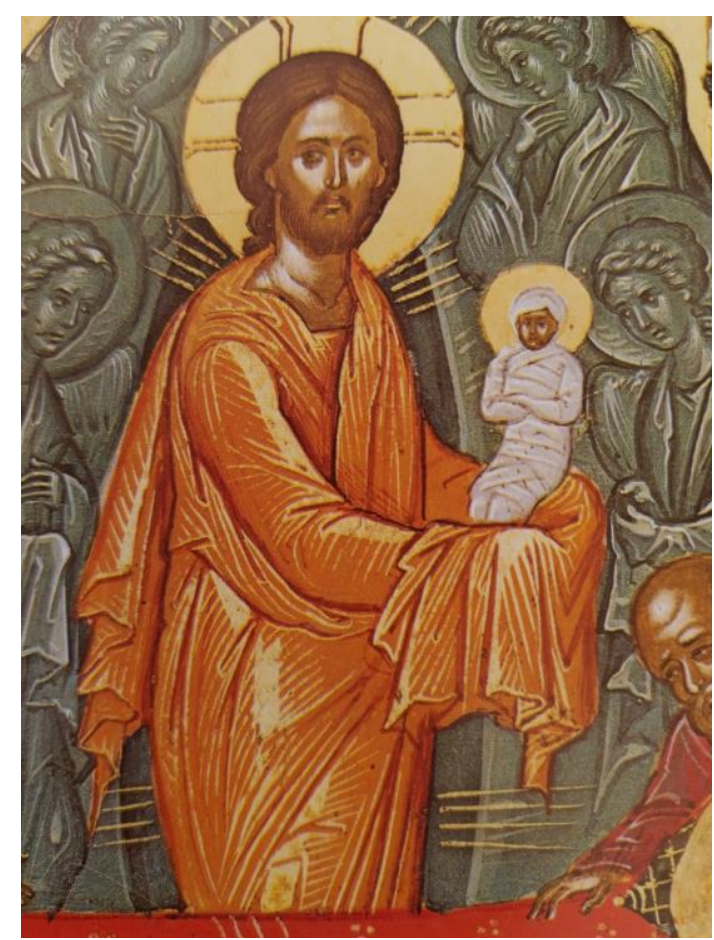

No centro e ao alto da cena, há o Espírito Santo sobre cabeça do Cristo e como que encimando a legião de anjos que chegam para saudar a Mãe de Deus.

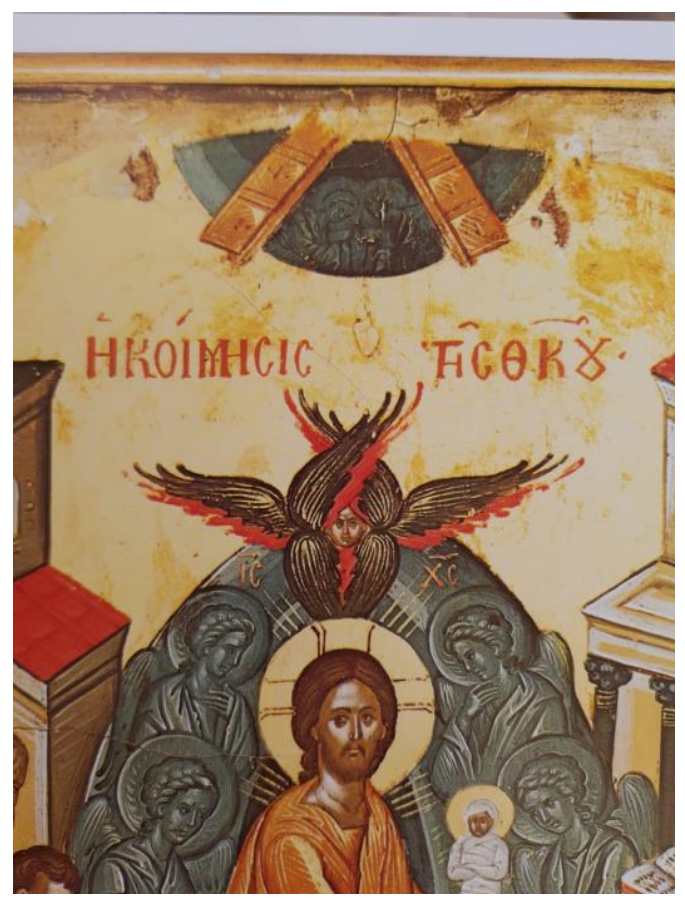

Note-se que os anjos não são coloridos, mas contrastam com as cores laranja e amarelo dourado das vestes do Cristo, bem como com sua auréola e com a da alma de Maria, ambas douradas. O Espírito Santo não está presente na descrição de Dionísio, mas as posições do Cristo, da alma de Maria e da Mãe de Deus que dorme estão em pleno acordo.

O apóstolo Pedro é apresentado à cabeceira da Theotókos, com um turíbulo, executado o gesto de incensar a que dorme. Aos pés da Panagía, há uma figura masculina que parece repetir a iconografia de São Paulo, igualmente, em sintonia com a descrição de Dionísio. 

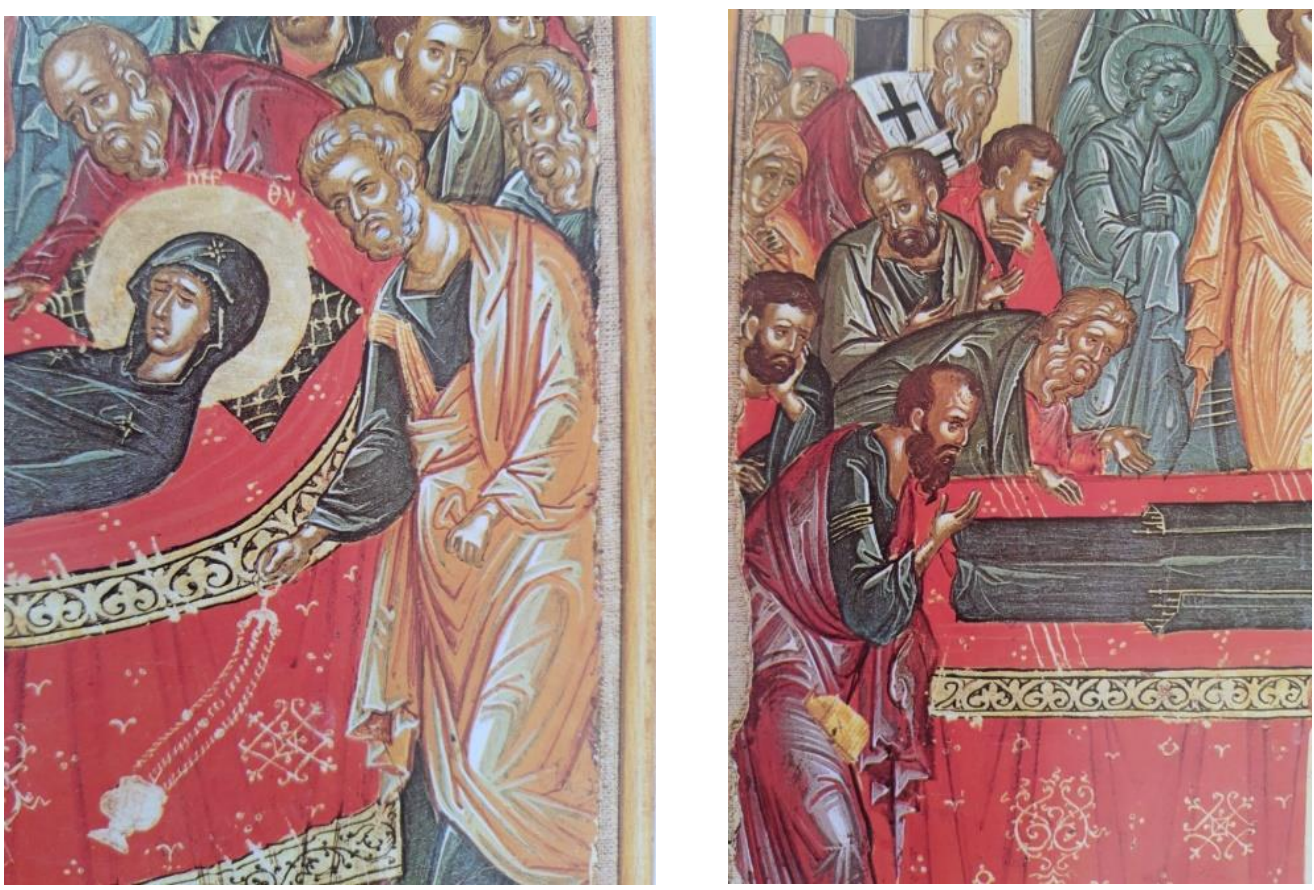

Os teólogos também estão presentes, bem como as mulheres que choram por Maria. Tendo por espécie de cenário de fundo algumas casas. Ou seja, dialogando com a descrição de Dionísio de Furna.

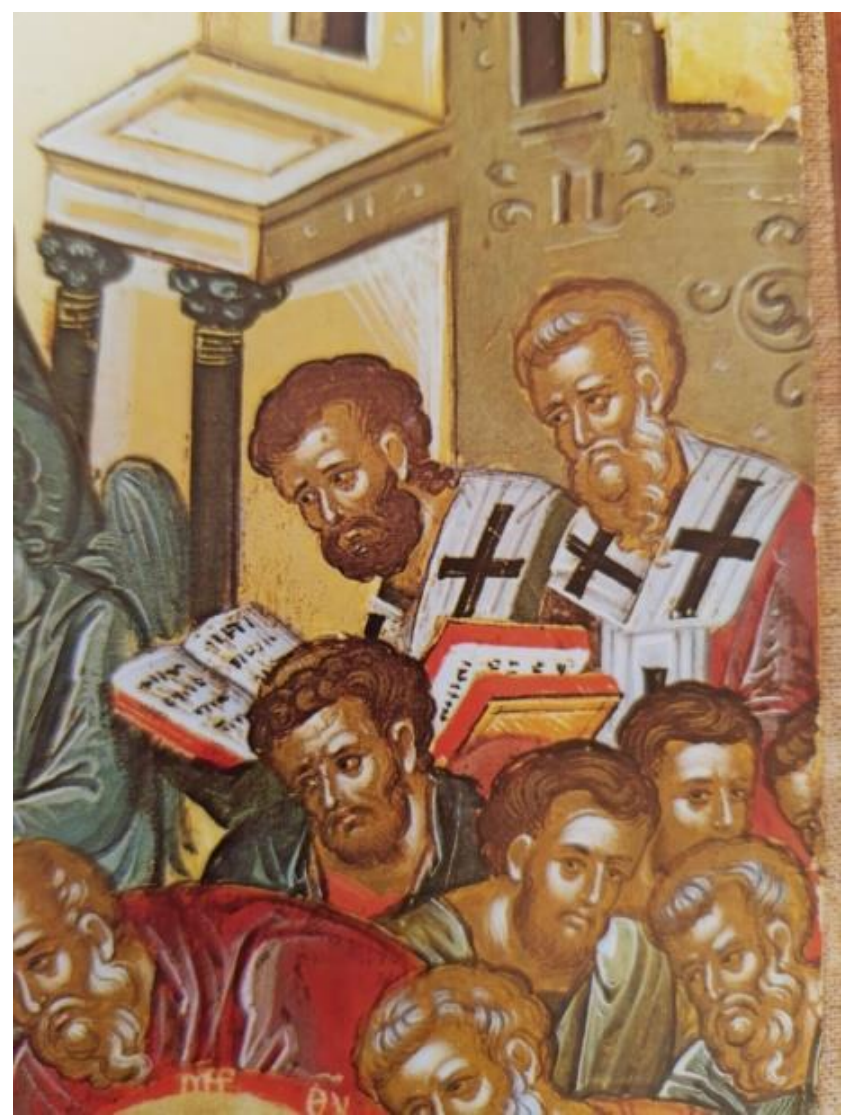

Interessante refletir, não apenas a respeito das diferenças e semelhanças entre as interpretações da mesma cena de celebração theomitérica, mas, sobretudo, ter em mente que há certa liberdade interpretativa antes da compilação das ordenações da iconografia bizantina 
realizada pela obra dionisíaca. Nesse sentido, a discussão de Hans Belting sobre o livro de Dionísio de Furna e a maneira como ele foi compreendido entra em conflito com o contraste exposto no presente trabalho. Por mais que haja um "manual do pintor do Monte Athos", como foi traduzido livremente o título da obra aqui estudada, ele é uma compilação posterior, como pontua Belting, e não dá conta das diferentes traduções pictóricas das cenas sagradas. Isso posto, definitivamente, o pintor não é escravo do Teólogo, como postulou Dridon ${ }^{13}$, até porque, como bem explica Belting, não há separação entre invenção e execução.

Assim, é escolha de Theophanis de Creta inserir a figura do Espírito Santo na "Dormição", como é escolha dele não inserir a imagem do judeu com os braços decepados pelo anjo. É evidente que há uma narrativa básica, mas essa será interpretada pelo pintor que é, igualmente, teólogo.

Esses foram apenas dois exemplos da representação desse episódio do culto da Panagía dentro da ortodoxia grega. Há exemplos inúmeros que o espaço do presente trabalho não poderia abarcar. Vale concluir o estudo mencionado a existência de uma nave consagrada à "Dormição da Mãe de Deus", em Kalambaca, Grécia. O templo data entre o s VII e o XI séculos, evidenciando a tradição do culto à Virgem e sua importância. Infelizmente, a pintura mural presente nesse edifício eclesiástico data do século XV, sendo considerada pós-bizantina e deixando seu visitante com a curiosidade sobre como seria a representação autenticamente bizantina da "Dormição".

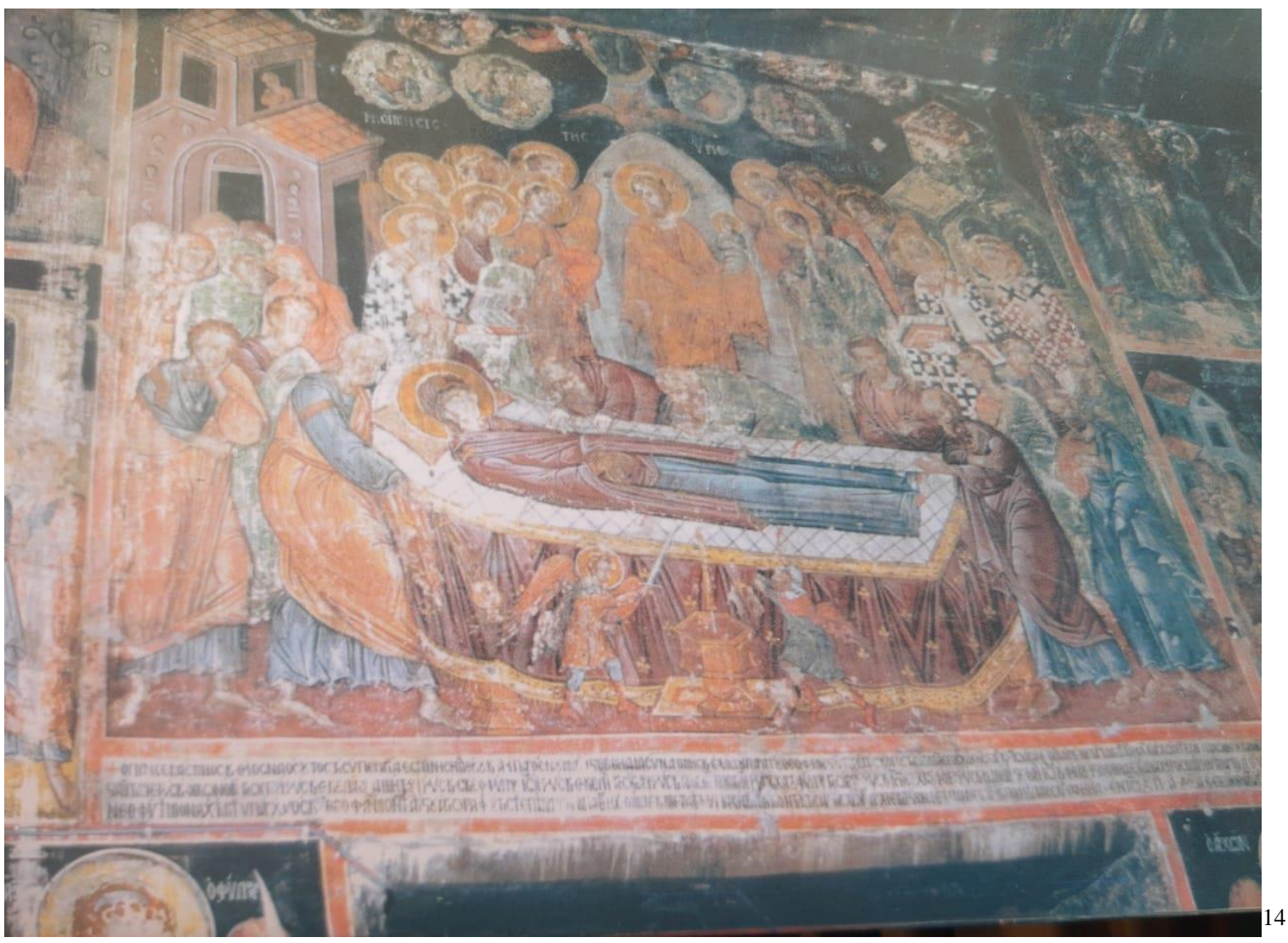

Termino o presente estudo pontuando a importância do texto de Dionísio de Fourna, de seu estudo e tradução. Sua relevância reside, não apenas a interpretação iconográfica das imagens de uma cultura Cristâ ortodoxa, mas, igualmente, na proposta de se ter uma espécie de

\footnotetext{
${ }^{13}$ Cf. BELTING, Hans. Semelhança e presença, a história da imagem antes da era da arte. Rio de Janeiro: s.n, 2010, p.20.

14 Templo sagrado da Dormição da Mãe de Deus, Kalambaca, Grécia.
} 
receituário de técnicas de pintura, objeto de minha investigação prática de pintura, uma vez que o autor oferece ao seu leitor uma espécie de passo-a-passo para a preparação material de suportes e têmperas. Assim, a obra em tela se mostra de extrema complexidade e, na mesma proporção, completa para registrar os processos vários da composição da chamada iconografia bizantina.

\section{Referências bibliográficas:}

BELTING, Hans. Semelhança e presença, a história da imagem antes da era da arte. Rio de Janeiro: s.n, 2010 .

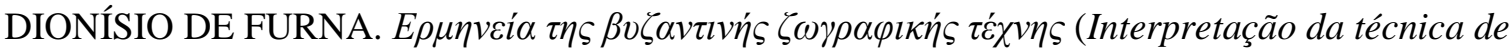
pintura bizantina). Atenas: Spanós, 1997.

ECCLESIA, portal. http://www.ecclesia.com.br/biblioteca/liturgia/doze_festas_dormicao.html. Acesso em 02/12/2020.

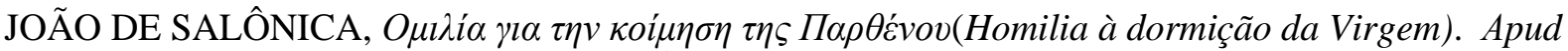

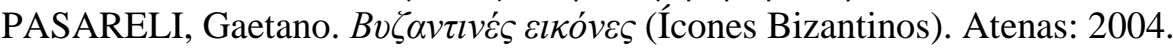

QUIRICO, Tamara. As funções do Juízo final como imagem religiosa. In: História [online]. 2010, vol.29, n.1, pp. 120-148.

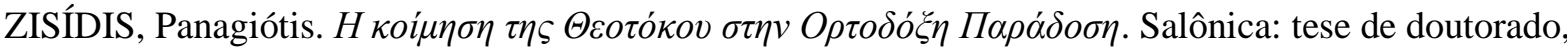
2002. 